\title{
1. The early usage of clinical guidelines in medical negligence litigation: an Anglo-American perspective ${ }^{1}$
}

\author{
Ash Samanta and Jo Samanta
}

\section{INTRODUCTION}

In medical negligence litigation a key step is for the claimant to prove that the doctor failed to meet the required standard of care. The traditional test in law for such cases is the Bolam test: a doctor is not negligent if what he has done would be endorsed by a responsible body of medical opinion in the relevant speciality at the material time. ${ }^{2}$ The standard has been seen by some commentators as being one set by the medical profession and evidenced by expert testimony, with minimal court scrutiny, and that stricter evaluation of such opinion would be welcome. ${ }^{3}$ The decision in Bolitho ${ }^{4}$ reinforced the notion that the court should be prepared to adopt a more interventionist stance when assessing expert evidence and in setting the standard of care. One approach towards a more objective measure for determining the standard of care could be through using evidence-based clinical guidelines ('guidelines').

Guidelines are consensus statements developed to assist clinicians in making decisions about treatment for specific conditions. ${ }^{5}$ They are developed

\footnotetext{
1 This chapter is based on and largely reproduces an earlier publication: A Samanta, MM Mello, C Foster, J Tingle and J Samanta, 'The role of clinical guidelines in medical negligence litigation: a shift from the Bolam standard?' (2006) 14 Medical Law Review 321-66 (permissions obtained). The authors (AS and JS) wish to thank the publishers of the Medical Law Review for their permission to use the article above as part of this chapter.

2 Bolam v Friern Hospital Management Committee [1957] 1 WLR 582.

3 H Teff, 'The standard of care in medical negligence: moving on from Bolam?' (1998) 18 OJLS 473.

$4 \quad$ Bolitho v City and Hackney Health Authority [1997] 4 All ER 771. 1997).

5 Department of Health, The New NHS: Modern, Dependable (TSO, London,
} 
systematically on the basis of evidence ${ }^{6}$ and aim to promote effectiveness and efficiency of healthcare delivery. ${ }^{7}$ It has long been argued that evidence-based practice could be used to develop a framework to ensure consistent access to services and quality of care across the country, an approach espoused by the Department of Health. ${ }^{8}$ To promote the development of evidence-based guidelines and end the practice of rationing treatment according to postcode locality the government created the National Institute for Clinical Excellence (NICE). ${ }^{9}$ The Healthcare Commission (HC) with its duty to monitor the implementation of such guidelines was also created as part of this government agenda for quality. ${ }^{10}$ Some commentators, however, believed that guidelines might serve to fetter clinical discretion and professional autonomy and define a standard for clinical practice that was too inflexible or unrealistic. ${ }^{11}$ Discretion lies at the heart of clinical judgement and must take into account a range of competing influences that are relevant to individual patient circumstances and clinical care. For this reason it has been argued that guidelines should not constitute a de facto legal standard to be applied rigidly in every case. ${ }^{12}$ A plethora of academic commentary now exists in both the legal and medical literature that analyses the theoretical basis as to why guidelines should, or should not, set the legal standard of care in clinical negligence litigation. ${ }^{13}$

Clinical guideline production began to gather momentum across the UK at the turn of the millennium, although they had been deployed across the US in clinical settings and used in medical malpractice litigation for at least 20 years previously. To our knowledge, there were no empirical data at that time on the

6 G Feder, M Eccles, R Groll, C Griffiths and J Grimshaw, 'Guidelines: using guidelines' (1999) 318 BMJ 728.

7 JH Wilson, Integrated Care Management: The Path to Success (Butterworth Heinemann, Oxford, 1999); Department of Health, NHS Executive: Guidelines (HMSO, London, 1996).

8 Department of Health, The New NHS: Modern, Dependable (HMSO, London, 1997).

9 NICE was established on 1 April 1999 as a special health authority created by statutory instrument (SI 1999 No. 220) under s. 11 of the National Health Service Act 1977. NICE has direct responsibility to the Secretary of State.

10 Section 19 of the Health Act 1999 established the Commission for Health Improvement which in April 2002 became the Commission for Healthcare Audit and Inspection and then subsumed in the Healthcare Commission.

11 D Black, 'The limitations of evidence' (1998) 32 Journal of the Royal College of Physicians of London 23.

${ }_{12}$ B Hurwitz, 'How does evidence based guidance influence determinations of medical negligence?' (2004) 329 BMJ 1024.

13 For a general discussion of guidelines in the context of medicine and law, see $\mathrm{J}$ Tingle and C Foster (eds), Guidelines: Law, Policy and Practice (Cavendish, London, 2002). 
actual or perceived use of guidelines in medical litigation in the UK. To fill this lacuna we embarked on a collaborative, interdisciplinary survey to determine practising lawyers' perceptions of the use of guidelines in medical negligence litigation across England and Wales.

The results revealed that a high proportion of respondent barristers and solicitors were familiar with guidelines and had used them as part of trial strategy. They expected that guidelines would play a far greater role in medical litigation in the future. On the basis of these findings, we argued that guidelines might serve to inform the legal standard of care (in respect of breach of duty) more proactively by representing a shift from the traditional Bolam standard. We do not purport to provide a comprehensive review of clinical guidelines in law, or to rehearse the rich corpus of arguments that underlies the philosophical basis of using guidelines to determine the standard of care. ${ }^{14}$ Instead, we focus on the practical application of guidelines based upon empirical observation. We draw upon experience from the US to inform the discussion and provide an Anglo-American perspective of the early usage of guidelines in England and Wales.

\section{BACKGROUND TO CHANGE}

At the turn of the millennium a range of cumulative pressures fuelled the need for transparency and accountability of medical practice. As a result, the traditional concept of clinical autonomy became constrained to a greater degree and medical practice became subject to a range of diverse factors. Social, political, professional, legal and consumer empowerment levers were key features behind this change. ${ }^{15}$

\section{Government Agenda}

At the time of the study, section 18 of the Health Act 1999 imposed a statutory duty of quality on all National Health Service (NHS) and Primary Care Trusts, to operate alongside the common law duty of care that was already owed to patients. The legislation required high-quality healthcare to be provided on a uniform basis. Guidelines were seen to mesh with this goal since the rationale

14 H Teff, 'Clinical guidelines, negligence and medical practice' in M Freeman and A Lewis (eds), Law and Medicine: Current Legal Issues Volume 3 (Oxford University Press, Oxford, 2000) 67-80; V Harpwood, 'The manipulation of medical practice', ibid. at 47-66.

15 For a more detailed view on the manipulation of medical practice, see $\mathrm{V}$ Harpwood, above, note 14 . 
behind their use is that high-level empirical evidence underpins best practice. ${ }^{16}$ Consequently, there was a strong political drive to promote the use of guidelines to assure the achievement and maintenance of cost-effective quality in healthcare provision. ${ }^{17}$ NICE formulates guidelines using an evidence-based approach with a view to furthering the goal of commitment to uniformity of healthcare quality and there was an expectation that its guidance would be implemented consistently across the NHS. ${ }^{18}$ The HC had a harder-edged function of inspection, as well as auditing of healthcare providers, ${ }^{19}$ and exerted a notable impetus to ensure that guidance from NICE was followed. ${ }^{20}$

The focus on quality within the NHS led to considerable investment in the healthcare system. Conceptually, 'quality' covers a range of areas. ${ }^{21}$ Towards the end of the last century the government described the agenda for quality in the NHS as 'doing the right things, at the right time, for the right people, and doing them right - first time'. ${ }^{22}$ Later, this vision was developed to incorporate the commitment to implementing quality assurance and quality improvement programmes using opportunities to involve patients and their representatives in decisions about their healthcare and in designing services, working with all stakeholders in determining clinical priorities and providing valid and relia-

16 For a detailed discussion on the formulation of guidelines and their development, see SH Woolf, 'An organised analytical framework for practice guideline development: using analytical logic as a guide for reviewing evidence, developing recommendations and explaining the rationale' in K McCormick, SR Moore and R Segal (eds), Methodology Perspectives (United States Department of Health and Human Services Agency for Health Care Policy and Research, Rockville, 1994) 105.

17 Department of Health, Using Clinical Guidelines to Improve Patient Care within the NHS (HMSO, London, 1996); Department of Health, The New NHS, above, note 5; Department of Health, An Organisation with a Memory (HMSO, London, 2000); Department of Health, Making Amends: A Consultation Paper Setting out Proposals for Reforming the Approach to Clinical Negligence in the NHS (HMSO, London, 2003); Department of Health, NHS Redress: Statement of Policy (HMSO, London, 2005).

18 Department of Health, A First Class Service: Quality in the New NHS (HMSO, London, 1998).

19 S Dewar and B Finlayson, 'The I in the new CHAI' (2002) 325 BMJ 848.

20 This chapter does not focus on NICE guidance in particular, but offers these arguments as background to the sociopolitical environment which might elevate guidelines as being representative of the expected standard of care. For a discussion on the extent to which NICE guidelines might influence the legal standard of care, see A Samanta, J Samanta and M Gunn, 'Legal considerations of guidelines: will NICE make a difference?' (2003) 96 Journal of the Royal Society of Medicine 133.

21 S Leatherman and K Sutherland, 'Evolving quality in the new NHS: policy, process and pragmatic considerations' (1998) 7 (supplement) Quality in Healthcare 54.

22 Department of Health, above, note 18. 
ble information about standards of clinical care. ${ }^{23}$ An open and participative culture within the NHS aims to provide transparent accountability at all levels of service provision. ${ }^{24} \mathrm{We}$ envisaged that wide and consistent use of guidelines might serve as a tool for individual and managerial accountability at a local level, as well as for formulating policy at national level. ${ }^{25}$

\section{A New Professionalism}

The General Medical Council (GMC) and medical Royal Colleges concurred that good practice should be measured against established guidelines and stressed the need for robust mechanisms to identify and maintain high standards in medical care. ${ }^{26}$ The GMC emphasised that in order to promote the required standards of professional practice, there needed to be effective quality assurance and clear professional accountability. ${ }^{27}$ To ensure good practice, doctors must be responsible for their own performance and conduct and should share responsibility for the quality of care provided by their teams. An effective team must be well managed and committed to the provision of a high-quality service. There is an expectation that in the process of quality improvement clinical teams will normally use recommended guidelines and that the approach taken by the team should go hand in hand with proposed NHS arrangements for modernisation. ${ }^{28}$ Standards to be followed are those set by the GMC, the Royal Colleges ${ }^{29}$ as well as NICE.

The findings of the Bristol Inquiry shook public confidence and called into question standards within the NHS. ${ }^{30}$ The fifth report of the Shipman Inquiry emphasised that it would not be sufficient for guidance to be implicit in the context and circumstances of clinical practice. ${ }^{31}$ This lack of explicit standards could result in inconsistent and widely varying decisions, as well as

23 Department of Health, A Commitment to Quality, a Quest for Excellence (HMSO, London, 2001).

24 Department of Health, above, note 18.

25 Department of Health, above, note 23.

26 General Medical Council, Good Medical Practice (GMC, London, 2001);

Federation of Royal Colleges of Physicians, Good Medical Practice for Physicians (RCP, London, 2001).

27 General Medical Council, 'Maintaining good medical practice' (GMC, London, 1998).

28 Department of Health, above, note 8.

29 General Medical Council, above, note 26.

30 Learning from Bristol: The Report of the Public Inquiry into Children's Heart Surgery at the Bristol Royal Infirmary 1984-1995 (Cmnd. 5207 2001).

31 Department of Health, Safeguarding Patients: Lessons Learned from the PastProposals for the Future. Fifth report (Cmnd. 6394 2004). 
tragic consequences for patients and their families. The development of specific and detailed standards was considered necessary to define the cohesive relationship between doctors and their patients. ${ }^{32}$ Clear standards with component terms were expected to form the basis of medical professionalism. ${ }^{33}$ A transparent synthesis of evidence and opinion is essential to gain public approval. Evidence-based practice was expected to promote public confidence. Fitness-to-practise criteria were to include not only standards of conduct, but also those that define professional performance. Clinical guidelines would be useful for identifying and addressing problems of physician underperformance.

The NHS Reform and Healthcare Professions Act 2002 introduced a further layer of regulatory control over healthcare quality. This Act established the Council for the Regulation of Healthcare Professionals which was known subsequently as the Council for Healthcare Regulatory Excellence. Following implementation of the National Health Service Reform and Health Care Professions Act 2002 the body then changed its name to the Professional Standards Authority for Health and Social Care, a body that represents patients and the public and reviews the work of the professional regulatory bodies. In the context of professional regulation, it was anticipated that established guidance might help to define the standard of practice expected. Knowledge transformation and consumer empowerment could raise societal expectations that good practice hinges on following established guidelines where these were clinically appropriate. ${ }^{34}$

\section{The Bolitho Judgment}

The ruling in Bolitho was expected to promote a shift away from reliance on Bolam. ${ }^{35}$ If this transpired it would no longer be sufficient that the standard of

32 R Rosen and S Dewar, On Being a Doctor: Redefining Medical Professionalism for Better Patient Care (King's Fund, London, 2004) https://www.kingsfund.org.uk/ publications/being-doctor accessed on 7 June 2021; s. 46 of the Health and Social Care (Community Health and Standards) Act 2003 sets out the legislative basis for healthcare standards.

33 R Baker, 'Developing standards, criteria and thresholds to assess fitness to practice' (2006) 332 BMJ 230.

34 It must be remembered that the value of guidelines is dependent upon how they are developed and on the synthesis of the evidence available. See, for example, PG Shekelle, SH Woolf, M Eccles and J Grimshaw, 'Guidelines: developing guidelines' (1999) 318 BMJ 593; and DJ Cook, CD Mulrow and RB Haynes, 'Systematic reviews: synthesis of best evidence for clinical practice' (1997) 126 Annals of Internal Medicine 376.

35 M Brazier and J Miola, 'Bye-bye Bolam: a medical litigation revolution?' (2000) 8 Med LR 85; A Samanta and J Samanta, 'Legal standard of care: a shift from the traditional Bolam test' (2003) 3 Clinical Medicine 443. 
care proclaimed by a defendant doctor would be satisfied merely because that standard was endorsed by a respectable body of peers. In obiter comments in Bolitho it was emphasised that the word 'responsible', in the traditional formulation of the Bolam test, meant that responsible practice was that which would withstand scrutiny from a judicial perspective. ${ }^{36}$ Clinical practice, however prevalent within the medical profession, might not withstand logical scrutiny if that practice is contrary to a clear consensus emerging from the evidence-base. Lord Browne-Wilkinson indicated that experts should direct their minds to the question of comparative risks and benefits to reach a defensible conclusion on the matter in question. ${ }^{37} \mathrm{~A}$ clinical conclusion which did not have risk analysis at its heart was unlikely to be deemed a responsible conclusion. Bolitho has called attention to this issue and might therefore take effect not only in determining the logical basis of the course of action followed by the defendant, but also by engaging more forcefully in assessing risks and benefits. ${ }^{38}$ Properly considered clinical guidelines would be expected to achieve the same. This consonance with doctrinal development could act as a further factor to ensure that evidence-based guidelines played a greater part in medical litigation proceedings. ${ }^{39}$

\section{Civil Procedure Rules}

The Civil Procedure Rules $1998(\mathrm{CPR})^{40}$ radically transformed the rules of court that govern clinical negligence actions. Practice directions orchestrate clinical negligence claims and pre-action protocols. The overriding objective of the CPR is the early, efficient and cost-effective resolution of claims. ${ }^{41}$ The rules require the use of alternative methods to resolve disputes as a key component in keeping with the overriding objective.

Compliance with the CPR may enhance the use of guidelines and evidence-based medicine in several ways. First, practising lawyers might have no option but to consider guidelines seriously when making preliminary assessments of the viability of clinical negligence cases. Second, guidelines might come to play an important part in pre-trial resolution where the alleged negligence has involved departure from guidelines or conformity with

\footnotetext{
36 See the analysis of Lord Browne-Wilkinson above, note 4, at 778 .

37 Ibid.

38 This argument is developed further in the discussion.

39 C Foster, 'Bolam: consolidation and clarification' (1998) 4 Healthcare Risk Report 5 .

40 The CPR came into effect on 26 April 1999.

41 C Foster, 'Civil procedure, trial issues and guidelines' in Guidelines: Law, Policy and Practice, above, note 13 at 111-20.
} 
accepted guidance (or, more rarely, where allegations relate to a failure to lay down or implement guidelines). Third, the CPR requires strict conformity with response times at clearly defined stages of a claim with a view to early closure of proceedings wherever possible. These rules may encourage complaints managers, lawyers and doctors to place heavier reliance on guidelines during dispute resolution. ${ }^{42}$

Guidelines are also implicated by CPR disclosure rules. The pre-action protocol aims to encourage a 'cards on the table' approach as early as possible. Standard disclosure ${ }^{43}$ requires parties to disclose only those documents on which the party relies; the documents which adversely affect his own case or adversely affect another party's case or supports another party's case; and documents which are required to be disclosed by a relevant practice direction. This default position may be varied if the parties agree, ${ }^{44}$ or if the court orders variance from the standard obligation. Clinical guidelines will be disclosa$b^{4} e^{45}$ where the alleged negligence involves a departure from guidelines, or alternatively where guidelines are used to exculpate the defendant by showing adherence to conduct that falls within their remit. If the claimant's preliminary letter before action raises issues as to which guidelines are relevant, then in the absence of an agreed variance order, it is unclear as to whether in these circumstances the guidelines must be disclosed. It has been postulated that, absent general caveats to the basic rule of disclosure, such as public interest immunity or confidential communications, failure to disclose guidelines is likely to be viewed dimly by the court. ${ }^{46}$ It was anticipated that this potential use of guidelines in the context of the CPR could result in their greater use in court.

\section{SURVEY AND RESULTS}

\section{Survey}

A two-page questionnaire was developed based on our knowledge of guidelines currently in use in clinical medicine in the UK and a literature review of the use of guidelines in medical litigation. A pilot questionnaire was tested and reformulated based on the feedback. The questionnaire contained 14 multipart questions covering respondent demographics and practice characteristics, familiarity with specific guidelines, and awareness and attitudes towards use of guidelines for evidentiary purposes in medical negligence litigation. Specific

\footnotetext{
See V Harpwood, above, note 14.

Part 31.6 of the CPR.

Ibid. at Part 31.5.

Ibid. at Part 31.6.

6 C Foster, above, note 41.
} 
Table 1.1 Demographic features of respondent $(n=110) *$

\begin{tabular}{|c|c|c|}
\hline & $n$ & $\%$ \\
\hline \multicolumn{3}{|c|}{ Legal practice type: } \\
\hline Barrister & 39 & 35.5 \\
\hline Solicitor & 71 & 32.3 \\
\hline \multicolumn{3}{|c|}{ Proportion of own caseload accounted for by clinical negligence cases: } \\
\hline$<10 \%$ & 5 & 4.5 \\
\hline $11-25 \%$ & 3 & 2.8 \\
\hline $26-50 \%$ & 13 & 11.9 \\
\hline $51-75 \%$ & 22 & 20.2 \\
\hline $76-90 \%$ & 21 & 19.3 \\
\hline$>90 \%$ & 45 & 41.3 \\
\hline \multicolumn{3}{|c|}{ Years practising law: } \\
\hline$<5$ years & 1 & 0.9 \\
\hline $6-10$ years & 18 & 16.5 \\
\hline $11-20$ years & 40 & 36.7 \\
\hline$>20$ years & 50 & 45.8 \\
\hline \multicolumn{3}{|c|}{ Proportion of firm's caseload accounted for by clinical negligence cases: } \\
\hline$<10 \%$ & 33 & 35.9 \\
\hline $11-25 \%$ & 24 & 26.1 \\
\hline $26-50 \%$ & 6 & 6.5 \\
\hline $51-75 \%$ & 20 & 21.7 \\
\hline $76-90 \%$ & 7 & 7.6 \\
\hline$>90 \%$ & 2 & 2.2 \\
\hline \multicolumn{3}{|c|}{ Annual number of new clinical negligence cases personally handled: } \\
\hline 0 & 1 & 0.9 \\
\hline $1-5$ & 5 & 4.6 \\
\hline 6-10 & 8 & 7.3 \\
\hline $11-15$ & 13 & 11.8 \\
\hline $16-20$ & 20 & 18.2 \\
\hline$>20$ & 63 & 57.3 \\
\hline \multicolumn{3}{|c|}{ Annual number of new clinical negligence cases handled by firm: } \\
\hline $0-5$ & 0 & 0 \\
\hline $6-10$ & 1 & 1.1 \\
\hline $11-15$ & 4 & 4.4 \\
\hline
\end{tabular}




\begin{tabular}{l|c|c}
\hline & \multicolumn{2}{c}{$n$} \\
\hline $16-20$ & 0 & 0 \\
\hline$>20$ & 87 & 94.6 \\
\hline
\end{tabular}

Note: * Percentage of completed responses. Percentages may not sum to 100 due to rounding.

enquiries were made about four types of guidelines: those emanating from the Royal Colleges, the National Societies, the National Institute for Health and Care Excellence (NICE) and the Scottish Intercollegiate Guidelines Network (SIGN). Responses to most questions were structured as a three- or four-point Likert scale.

Solicitors and barristers practising in clinical negligence in England and Wales were identified using the Chambers UK Guide to the Legal Profession 2004 and the Legal 500 Directory 2004. The questionnaire and a cover letter were mailed to 372 lawyers (220 solicitors and 152 barristers). ${ }^{47} \mathrm{~A}$ total of 110 lawyers completed the survey (71 solicitors, 39 barristers).$^{48}$ The data were analysed descriptively and several respondent subgroup comparisons were tested. ${ }^{49}$

\section{Respondent Characteristics}

Approximately two-thirds of the respondents were solicitors and one-third were barristers (Table 1.1). Forty-four per cent were based in London. Seventy-four per cent of respondents represented claimants more than they did defendants. Respondents were experienced in terms of duration of practice and handling of clinical negligence cases. Eighty-three per cent had been in legal practice for 11 years or more, 81 per cent had clinical negligence cases as more than half of their personal caseload, and 75 per cent handled more than 15 new clinical negligence cases per year.

${ }^{47}$ Questionnaires were identified by numeric identifiers only to preserve respondents' confidentiality. A reminder was mailed to non-responders after 8 weeks.

48 The unadjusted response rate was 30 per cent.

49 A research assistant entered coded responses onto an Excel spreadsheet. One of the investigators analysed the data using the Stata 8.2 statistical package. Bivariate associations were examined using chi-square analysis and Cuzick's extension of the Wilcoxon rank-sum test for trend across ordered responses: see JA Cuzick, 'Wilcoxon-type test for trend' (1985) 4 Statistics in Medicine 87. Results described as 'statistically significant' are those for which the test statistic rejected the null hypothesis of no difference between the comparison groups at a $p$-value of $<0.05$ or smaller. A $p$-value (or probability value) of $<0.05$ indicates that there is less than a 5 per cent chance that the result occurred purely by chance. 


\section{Familiarity with Guidelines}

A high percentage of respondents reported that they were somewhat familiar with each of the major guidelines, although a relatively small proportion described themselves as being very familiar with them (Table 1.2). Overall, 80 per cent of respondents were very familiar, or somewhat familiar, with guidelines from the various Royal Colleges, 75 per cent were familiar with NICE guidelines and 46 per cent were familiar with guidelines from learned national societies. Solicitors were more familiar than barristers with guidelines from NICE $(p<0.01)$.

Table 1.2 Lawyers' familiarity with clinical guidelines $(n=110) *$

\begin{tabular}{l|cc|c}
\hline How familiar are you with guidelines from ... & \multicolumn{3}{c}{$\%$} \\
\cline { 2 - 4 } & Very familiar & $\begin{array}{c}\text { Somewhat } \\
\text { familiar }\end{array}$ & $\begin{array}{c}\text { Not at all } \\
\text { familiar }\end{array}$ \\
\hline The Royal Colleges & 16.7 & 63.9 & 19.4 \\
\hline $\begin{array}{l}\text { National Societies (e.g., British Society of Rheumatology, } \\
\text { British Society of Dermatology, British Society of } \\
\text { Haematology) }\end{array}$ & 1.9 & 43.9 & 54.2 \\
\hline Scottish Intercollegiate Guidelines Network (SIGN) & 0.0 & 6.5 & \\
\hline National Institute for Clinical Excellence (NICE) & 13.6 & 60.9 & 25.5 \\
\hline
\end{tabular}

Note: * Percentage of completed responses. Percentages may not sum to 100 due to rounding.

\section{Use of Guidelines in Litigation}

\section{Observed use of guidelines in negligence actions}

Eighty-nine per cent of respondents reported that they, or someone on their team, had used guidelines in medical negligence cases that they had handled in the past 3 years ( 17 per cent often or very often, and 72 per cent sometimes) (Table 1.3). A similar proportion had seen guidelines used in a case by the opposing side during the past 3 years. Lawyers were somewhat more likely to report having seen guidelines used for inculpatory purposes (87 per cent) than for exculpatory purposes (79 per cent).

The most prevalent specific use of guidelines was citation in medical expert reports ( 25 per cent very often/often, 69 per cent sometimes). Around half the respondents reported seeing guidelines used in each of the following ways: by a witness during his or her testimony, by a lawyer in direct examination of a witness and by a lawyer during cross-examination. Significantly more barristers than solicitors reported having observed the use of guidelines during examination-in-chief $(p=0.02)$, during cross-examination $(p=0.01)$, in decid- 
ing the case in favour of claimants $(p=0.01)$ and in deciding the case in favour of defendants $(p=0.01)$.

Table 1.3 Lawyers' observed uses of guidelines in clinical negligence litigation $(n=110) *$

\begin{tabular}{|c|c|c|c|c|}
\hline \multirow{2}{*}{$\begin{array}{l}\text { In clinical negligence cases you have handled as a lawyer } \\
\text { during the last } 3 \text { years, how often have guidelines ... }\end{array}$} & \multicolumn{4}{|c|}{$\%$} \\
\hline & $\begin{array}{l}\text { Very } \\
\text { often }\end{array}$ & Often & Sometimes & Never \\
\hline \multicolumn{5}{|l|}{ Parties using: } \\
\hline Been used in a case by you or your team? & 0.9 & 16.5 & 71.6 & 11.0 \\
\hline Been used in a case by the opposing side? & 0.9 & 7.5 & 71.0 & 20.6 \\
\hline \multicolumn{5}{|l|}{ Purpose of use: } \\
\hline $\begin{array}{l}\text { Been used (by anyone in the case) to help prove that a doctor } \\
\text { did not meet the standard of care? }\end{array}$ & 0.9 & 10.9 & 75.5 & 12.7 \\
\hline $\begin{array}{l}\text { Been used (by anyone in the case) to help prove that a doctor } \\
\text { did meet the standard of care? }\end{array}$ & 0.9 & 10.3 & 67.3 & 21.5 \\
\hline \multicolumn{5}{|l|}{ Method of use: } \\
\hline Been cited in a medical expert's report? & 2.7 & 21.8 & 69.1 & 6.4 \\
\hline Been cited by a witness during his/her testimony in court? & 0.9 & 4.7 & 43.0 & 51.4 \\
\hline Been cited by a lawyer in the direct examination of a witness? & 1.0 & 1.9 & 46.7 & 50.5 \\
\hline Been cited by a lawyer during cross-examination of a witness? & 0.9 & 2.8 & 48.6 & 47.7 \\
\hline \multicolumn{5}{|l|}{ Effect of use: } \\
\hline Influenced the court to decide in favour of the Claimant? & 0.9 & 5.0 & 39.0 & 56.0 \\
\hline Influenced the court to decide in favour of the Defendant? & 1.0 & 3.0 & 44.0 & 52.0 \\
\hline
\end{tabular}

Note: * Percentage of completed responses. Percentages may not sum to 100 due to rounding.

Just over 40 per cent of respondents believed that the use of guidelines had been influential in the court's decision in clinical negligence cases. Forty-four per cent perceived that the guidelines had influenced the court to decide in favour of the claimant ( 5 per cent often, 39 per cent sometimes) and 48 per cent felt they had influenced the court in the defendant's favour (4 per cent very often/often, 44 per cent sometimes). Of those who reported seeing guidelines used for inculpatory purposes, 48 per cent believed the guidelines had swayed the court towards the claimant at least sometimes. Of those who had seen guidelines introduced for exculpatory purposes, 55 per cent believed that they had influenced the court to decide in favour of the defendant at least sometimes. Barristers were more likely than solicitors to report that guidelines had 
been influential in court decisions for both claimants $(p=0.01)$ and defendants $(p=0.001)$.

\section{Observed use of specific guidelines}

The Royal Colleges' guidelines were reported to be used most often in clinical negligence litigation. Eighty-three per cent of respondents had seen them used at least sometimes during the past 3 years (Table 1.4). Reported use of other guidelines was substantially lower. Solicitors reported greater observed use of NICE guidelines than barristers $(p<0.01)$.

\section{Table 1.4 Lawyers' observed uses of particular guidelines in litigation} $(n=110)^{*}$

\begin{tabular}{l|c|c|c|c}
\hline In clinical negligence cases you have handled as a lawyer & \multicolumn{5}{c}{$\%$} \\
\cline { 2 - 6 } $\begin{array}{l}\text { during the last } 3 \text { years, how often have each of the following } \\
\text { guidelines been used by someone in the case? }\end{array}$ & $\begin{array}{l}\text { Very } \\
\text { often }\end{array}$ & Often & Sometimes & Never \\
\hline The Royal Colleges & 1.9 & 13.1 & 68.2 & 16.8 \\
\hline $\begin{array}{l}\text { National Societies (e.g., British Society of Rheumatology, } \\
\text { British Society of Dermatology, British Society of } \\
\text { Haematology) }\end{array}$ & 0.9 & 0.9 & 38.3 & 59.8 \\
\hline Scottish Intercollegiate Guidelines Network (SIGN) & 0 & 0 & 2.8 & 97.2 \\
\hline National Institute for Clinical Excellence (NICE) & 0.9 & 6.5 & 43.5 & 49.1 \\
\hline
\end{tabular}

Note: * Percentage of completed responses. Percentages may not sum to 100 due to rounding.

\section{Perceived future use of guidelines}

The majority of respondents felt that several developments would lead to increased use of guidelines in litigation in the future (Table 1.5). The key drivers were thought to be the remit of NICE ( 85 per cent), clinical governance agendas ( 75 per cent), public awareness of guidelines ( 70 per cent) and efforts by patient-centred organisations ( 67 per cent). Many ( 48 per cent) also felt that Bolitho ${ }^{50}$ would be influential in promoting the use of guidelines in litigation.

50 Above, note 4. 
Table 1.5 Lawyers' perceptions of factors influencing the future use of guidelines in litigation $(n=110) *$

\begin{tabular}{l|c|c|c}
\hline \multirow{2}{*}{$\begin{array}{l}\text { Do you think any of the following will affect the future } \\
\text { use guidelines in litigation? }\end{array}$} & \multicolumn{3}{c}{$\%$} \\
\cline { 2 - 4 } & \multicolumn{1}{c}{$\begin{array}{c}\text { Yes, will } \\
\text { increase use } \\
\text { of guidelines }\end{array}$} & \multicolumn{1}{c}{$\begin{array}{c}\text { Yes, will } \\
\text { decrease use } \\
\text { of guidelines }\end{array}$} \\
\hline The remit of NICE & 85.2 & 0.0 & 14.9 \\
\hline Clinical governance agendas & 74.7 & 1.1 & 24.2 \\
\hline Patient awareness & 70.0 & 0.0 & 30.0 \\
\hline Patient-centred organisations & 67.0 & 0.0 & 33.0 \\
\hline The judgment in the case of Bolitho & 48.0 & 0.0 & 55.0 \\
\hline
\end{tabular}

Note: * Percentage of completed responses. Percentages may not sum to 100 due to rounding.

\section{DISCUSSION}

Our results indicated that a high proportion of practising lawyers in England and Wales had used guidelines, and had witnessed their use by others, during the litigation process which supported our hypothesis that guidelines might act as legal standards governing liability ${ }^{51}$ The potential utility of guidelines in litigation is underscored by doctrinal developments, most prominently the shift away from Bolam $^{52}$ towards more extrinsic evidence as to what constitutes reasonable care. This shift was perceived to be useful in combating potential problems of cognitive bias in expert testimony. ${ }^{53}$ Other forms of empirical evidence, such as physician survey responses concerning hypothetical vignettes of issues that are litigated, ${ }^{54}$ could also be employed to establish the legal standard, although there was little evidence that these were being used. Our

51 CC Havinghurst, 'Practice guidelines as legal standards governing physician liability' (1991) 54 Law and Contemporary Problems 87.

52 Whereas expert testimony may be based primarily on personal experience, it is assumed that this experience is a conglomeration of factors that includes objective medical evidence. The more recent call for objectivity in determining the legal standard of care is based on trying to develop models whereby objective empirical evidence takes precedence over personal experience.

${ }_{53}$ See W Meadow and J Lantos, 'A proactive database determination of the standard of medical care in pediatrics' (1998) 101 Pediatrics 6. This paper cites several psychological studies quantifying the phenomena of recall bias.

${ }^{54}$ A Hartz, J Lucas, T Cramm, M Green, S Bentler, J Ely, S Wolfe and P James, 'Physician surveys to assess customary care in medical malpractice case' (2002) 17 Journal of General Internal Medicine 546. 
results indicate that practising lawyers in England and Wales use guidelines as part of the litigation process.

\section{England and Wales}

\section{Appellate courts}

At the time of the study the higher courts had never been asked to pronounce definitively on the role of guidelines as standards for liability in clinical negligence. Notwithstanding this the courts have indicated the relevance of guidelines for consent as well as the appropriateness of a doctor's conduct in relation to withholding or withdrawing life-supporting treatment at the end of life.

The House of Lords in Bland, for example, had considered guidelines produced by the Medical Ethics Committee of the British Medical Association (BMA) regarding the discontinuation of artificial nutrition and hydration. Lord Goff noted that if a doctor acted 'in accordance with the medical practice now being evolved by the Medical Ethics Committee of the BMA, he will be acting with the benefit of guidance from a responsible and competent body of relevant professional opinion, as required by the Bolam test' ${ }^{55}$ Although their Lordships had made an independent study of the document and did not accept it automatically on the basis of its authority, as a publication from an eminent professional organisation, they did find that it represented a responsible body of medical opinion.

Similar conclusions were reached by the Court of Appeal in Burke $e^{56}$ regarding GMC guidance on decision-making in respect of life-prolonging treatment. ${ }^{57}$ The claimant, who suffered from a progressive degenerative neurological condition, expressed his wish to receive artificial nutrition and hydration (ANH) during the final stages of life, and that he did not want this either withdrawn or withheld on the basis of a decision taken by doctors that his life was no longer worth living. Such a decision by doctors would be supported by and in accordance with GMC guidance, which he contended was incompatible with his human rights. At first instance, Munby J held on the basis of a powerful rights-based discourse that the GMC guidance was incompatible with the rights under the Convention. ${ }^{58}$ The Court of Appeal reversed

\footnotetext{
55 Airedale NHS Trust v Bland [1993] 1 All ER 821 (emphasis added).

56 Burke v General Medical Council (defendant) and Disability Rights Commission (interested party) and the Official Solicitor (intervenor) [2005] EWCA 103.

57 General Medical Council, Withholding and Withdrawing Life-Prolonging Treatments: Good Practice in Decision-Making (GMC, London, 2002).

58 The first-instance decision in Burke ([2004] EWHC 1879) raised a number of issues, including determination of the best interests for persons who lack capacity, engagement of Article 3 of the Convention of Human Rights in end-of-life
} 
the decision, ${ }^{59}$ thereby implying (and in congruence with the Bland principle) that, in the context of withholding or withdrawing life-supporting treatment in the incompetent patient, a doctor's practice in acting in conformity with guidance from a responsible professional body would be in keeping with reasonable practice. ${ }^{60}$

The references to guidelines in Bland and Burke were in relation to the withholding or withdrawal of life sustaining treatment. It is arguable that in the context of such decisions the courts would be more willing to give greater weight to guidance endorsed by relevant clinical opinion on the basis that the principal determinative in such cases is the medical prognosis of the patient. This may not necessarily reflect the view taken in relation to guidelines representing a purported standard of care in litigation.

\section{First-instance decisions}

There is limited evidence of the use of guidelines in determining the standard of care in courts at first instance. The High Court in $R e C^{61}$ commented on guidance from the Royal College of Paediatrics and Child Health. ${ }^{62}$ In approving the guidance, the court stated that what had been proposed by the attending doctors with regard to the withdrawal of treatment had the support of reliable opinion from the College, and was therefore justified. In Early, ${ }^{63}$ the claimant alleged that a particular procedure used by the defendant anaesthetist was faulty. The procedure for intubation had been based on guidelines that had initially been stated orally but which were later reduced to writing. Bennett J noted that '[i]n relation to this procedure, it was put before the Division of Anaesthesia in the hospital. All the consultants at Newham got together ... then decided that this was a proper procedure to follow and minutes of the discussion were kept'. In this pre-Bolitho judgment, the judge accepted the guidelines as the standard of reasonable medical practice and found in favour of the defendant because it was persuasive that the guidelines had been reviewed at a meeting of the consultants. In a more recent case ${ }^{64}$ an obstetrics senior registrar employed by an

decision-making and the status of advance decisions that seek to receive clinically assisted nutrition and hydration to be given where doctors do not agree that this is in the best interests of the person.

59 Above, note 56.

60 The Court of Appeal did not address some of the wider issues raised by the first-instance decision on the basis that these were not relevant on the facts.

${ }_{61} \operatorname{Re} C$ (a minor) (medical treatment) [1998] Lloyd's Rep. Med. 1.

62 Entitled 'Withholding or withdrawing life saving treatment in children, a framework for practice'.

63 Early $v$ Newham Health Authority [1994] 5 Med LR 214.

${ }^{64}$ DF (by her litigation friend and mother CF) $v$ St George's Healthcare NHS Trust [2005] EWHC 1327. 
NHS Trust performed an instrumental delivery at a time when guidance from the Royal College of Gynaecologists and Obstetricians stipulated that this was not acceptable medical practice. The child sustained injuries at birth. In finding for the claimant, Gray $\mathrm{J}$ held that these guidelines, which would have been circulated to medical staff prior to the date of the incident, gave a clear and authoritative indication that to attempt instrumental delivery at that time of the claimant's birth (prior to full dilatation of the cervix) was not acceptable practice. These cases indicate that guidelines have been used in litigation for both claimants and defendants.

In Thomson ${ }^{65}$ a general practitioner failed to observe published guidance when advising parents of a child about the vaccine for measles, mumps and rubella. On medical advice the child had not been vaccinated and subsequently contracted measles. Meningitis developed as a complication with the tragic result of permanent brain damage. The first-instance finding was in favour of the claimant; the doctor was found to have breached the standard of care by not following relevant guidelines. On appeal, however, the case failed on causation and the Court of Appeal consequently avoided grappling with the issue of the relationship between the standards embodied in the guidelines and the legal standard of care. ${ }^{66}$ More recently in Penney, ${ }^{67}$ Peppitt J tested the evidence of experts using the Bolitho approach (that expert evidence should be able to withstand logical analysis), and stated: 'I do not consider that the evidence of Drs Hudson and Boon (defendant experts) stands up to logical analysis as that phrase was used by Lord Brown-Wilkinson in Bolitho. ... This is not to disparage the evidence of either. It is rather that in my judgment, their opinions cannot stand.' The Court of Appeal upheld the analysis (and decision) of the judge at first instance, approving the more interventionist stance for determining the standard of care. It follows that questioning the use (or lack) of national guidelines by the court would form part of this interrogative approach.

\section{Use by lawyers}

To date there has been no empirical research in the UK on the use of guidelines by lawyers. Respondents in our survey were most familiar with, and had most often seen used, guidelines from the Royal Colleges, followed by guidelines from NICE and other national learned societies. The findings concerning the Royal College guidelines are unsurprising in the light of the Colleges' longstanding recognition as authoritative professional bodies. Lawyers' familiarity

\footnotetext{
65 Thomson $v$ James and others (1996) 31 BMLR 1.

66 V Harpwood, Modern Tort Law (Cavendish, London, 2003).

67 Penney, Palmer and Cannon v East Kent Health Authority [2000] Lloyd's Rep. Med. 41.
} 
with, and the use of, guidelines from NICE is more interesting. NICE guidelines appear to have taken root in the legal community to an even greater extent than those from other learned national societies which have been in existence for a longer time. This level of heightened awareness is congruent with the current political, social and legal climate in the UK and is reflected in the stated higher prevalence of the use of NICE guidelines in litigation by lawyers. These factors may be mutually reinforcing: the greater lawyers' familiarity with the NICE guidelines, the more likely they may be used; the more often they are used, the more they may become known and accepted by judges.

Solicitors reported a significantly higher awareness of NICE guidelines compared to barristers. It is possible that the level of awareness among solicitors might be related to their perception of their potential benefit. Another explanation might be that solicitors tend to use such guidelines at an early stage of dispute resolution. This would concur with the objective of the CPR to facilitate early resolution of cases and promote alternative dispute resolution.

In terms of actual use of guidelines, we found that nine out of ten respondents stated that they had used guidelines in litigation proceedings during the past 3 years and a similar proportion reported seeing guidelines used by the opposing side. These findings chime with lawyers' reported knowledge about guidelines from authoritative sources. Our study also shows that guidelines have been used by both claimants and defendants although there was no statistically significant difference between these groups to suggest either a greater inculpatory or exculpatory use.

The reported prevalence of the use of guidelines in our study is considerably higher than that reported by a similar, but not equivalent, study from the US. ${ }^{68}$ Our study cannot be compared directly with the US study due to differences in methodology, recall periods ( 1 versus 3 years), samples (two insurers and a random survey of attorneys in 50 states versus all solicitors and barristers handling clinical negligence litigation in England and Wales) and response rates (approximately 60 per cent versus approximately 30 per cent). Despite these differences, our study provides suggestive evidence that the current use of guidelines in the UK may be higher than their use in the US a decade earlier. There is, however, no up to date evidence from the US to make a contemporaneous comparison. Furthermore, data from the National Audit Office indicates a steep rise both in clinical negligence claims and settlements which might be an additional factor for the higher use of guidelines observed in this study. There has been considerable concern about the possible escalation of future costs, the unpredictability of claim outcomes and the length of litigation, all of

68 A Hyams, J Brandenburg, S Lipsitz, D Shapiro and T Brennan, 'Practice guidelines in malpractice litigation: a two-way street' (1995) 122 Annals of Internal Medicine 450. 
which could be potentially ameliorated through the application of guidelines. ${ }^{69}$ Just over 40 per cent of respondents believed that their use had actually influenced the outcome of cases. One reason for this relatively low figure might be that guidelines are used mainly to inform the standard of care rather than being determinative, and are taken as one piece of relevant evidence. ${ }^{70}$

\section{The United States}

\section{Case law}

Reported cases from the US reveal that guidelines have been used both as a 'shield' (for exculpatory purposes by the defendants) and as a 'sword' (for inculpatory purposes by the claimant). ${ }^{71}$ They are not treated as dispositive, but are considered as one piece of evidence among others that bear on the determination of liability.

Non-adherence to established guidelines does not necessarily bode an adverse outcome for the defendant. The claimants in Lowry ${ }^{72}$ argued that the defendant doctor had deviated in an arbitrary manner from established guidelines of the American Heart Association for advanced cardiac life support, in that the defendant had administered atropine rather than epinephrine. ${ }^{73}$ The defendant argued that guidelines were not mandatory and could be overridden by the requirements of an individual case based upon clinical judgement. The appeal court affirmed the judgment in favour of the defendant; it did not see the guidelines as being more persuasive than the facts of the case itself or the evidence provided by expert witnesses.

Equally, adherence to guidelines may not exonerate the defendant. A standard of care proffered as adequate and supported by customary practice that is based on guidelines (as opposed to being based solely on responsible opinion) was rejected in Helling. ${ }^{74}$ The Washington Supreme Court, in allowing the claimant's appeal, refused to be bound by widely endorsed guidelines that formed the basis of the standard asserted by the defendant. This case is viewed as something of an aberration, however, and has not often been followed. Other

\footnotetext{
69 National Audit Office, Handling Clinical Negligence Claims in England: Report by the Comptroller and Auditor General (NAO, London, 2001).

70 It was beyond the scope of this to undertake an analysis of reported cases to assess whether legal practitioners' perceptions about the relevance of guidelines in determining the outcome of the case are borne out.

${ }_{71}$ This chapter does not propose to delve into a detailed analysis of the use of guidelines in litigation in the US as there is already a corpus of literature on the subject.

72 Lowry v Hendry Mayo Newhall Memorial Hospital 229 Cal 620 (1986).

73 Epinephrine and atropine increase the heart rate by different physiological pathways and mechanisms.

74 Helling v Carey 519 2D 981 (Wash 1974).
} 
courts have taken into account further sources of information in determining the standard of care, including factors such as the hospital's own procedures and policies and any other 'voluntary' standards. ${ }^{75}$

Overall, the US courts have been permissive towards the use of guidelines in determining the standard of care in medical malpractice litigation, moving away from sole reliance upon opinion-based customary practice. Guidelines have been advanced by both parties in litigation and compliance or non-compliance does not invariably inculpate or exculpate the physician, nor are guidelines per se binding in any way. The role of guidelines as a standard for legal liability is not straightforward. However, one principle that emerges with relative clarity from the US experience is that guidelines function as a facet of evidence that is informative, rather than determinative, of the standard of care expected.

\section{An affirmative defence}

Although the common law approach in the US is not to treat guidelines as dispositive, there has been statutory experimentation with making guidelines definitive of the expected standard of care for purposes of creating an affirmative defence. The state of Maine initiated a statutory demonstration project which provided an affirmative defence for physicians who voluntarily agreed to follow established clinical practice guidelines in four speciality areas. ${ }^{76}$ The purpose was to provide physicians with greater certainty as to what was expected from them and to reduce the need for practising defensive medicine. Anaesthesia, emergency medicine, radiology, and obstetrics and gynaecology were chosen as it was believed that these areas were most highly affected by costly negligence claims, leading to a high degree of defensive medical practice. Specialist advisory committees were formed and funded to commission guidelines based on good evidence and methodologically sound processes. The outcome of this large, well-resourced project was frustratingly unclear due to several factors. These included lack of reliable data available from managed care and other healthcare plans, lack of appropriate tools to measure whether a reduction (if any) in defensive practices was influenced by legislation, and the use of clinical judgement in instigating investigations over and above those prescribed by the guidelines in order to avoid missing diagnoses that

Denton Regional Medical Centre v Lacroix 947 SW 2D 941 (Tex Appeal 1997).

76 See RP Solomon, 'Guidelines in the United States: perspectives on law and litigation' in Guidelines: Law, Policy and Practice, above, note 13 at 137-59; M Bagle, 'Maine physician practice guidelines: implications for medical malpractice litigation' (1995) 47 Med LR 69; GW Kuc, 'Practice parameters as a shield against physician liability’ (1994) 10 Journal of Contemporary Health Law Policy 439. 
could have a critical effect on the patient. ${ }^{77}$ It is known that only a handful of physicians availed themselves of the safe harbour erected by the demonstration project. ${ }^{78}$ The reasons for the low uptake were not clear; two possibilities were that either the group of physicians covered by the statute was too narrow, or that the guidelines were not relevant to any of the malpractice cases that arose during the period of the demonstration project.

Florida also established a project to evaluate the effect on the costs of defensive medicine and professional liability of allowing compliance with practice guidelines to constitute an affirmative defence. ${ }^{79}$ An evaluation of the project concluded that the availability of the defence was an insufficient incentive to reduce defensive medical practice. Furthermore, it could not be determined what effect the use of guidelines had on insurance premiums or on the frequency of malpractice claims in Florida.

The main point of interest that emerges from these projects is that they create an asymmetry: a physician is deemed not to be negligent if the conduct in question falls within the auspices of approved guidelines. However, failure to comply with guidelines does not constitute prima facie evidence of negligence. Such a rule can be problematic and runs the risk of precluding potentially meritorious claims. For example, where a physician's practice has been conducted on the basis of a minimalist approach but in compliance with a relevant guideline, lawyers or courts may turn away patients who have been injured by negligence that takes the form of not departing from or adding to a guideline when particular circumstances call for such conduct. Guidelines cannot account for every contingency that might occur in clinical decision-making and are at best summaries of the most common clinical management pathways. They cannot be used to supplant clinical judgement where special action is merited ${ }^{80} \mathrm{It}$ is debatable whether there is a greater need in terms of societal policy to protect physicians from negligence liability compared to other groups of defendants, as the cost for litigation is high in other areas as well as in medicine.

A further question about the Maine approach is whether the use of guidelines in this manner would violate the constitutional requirements of the US Constitution concerning 'due process' and 'equal protection of the law'. These issues have not yet been tested and may constitute barriers to permitting the use of guidelines only as an affirmative defence.$^{81}$ In any event, the current

77 Ibid.

78 GH Smith, 'A case study in progress: practice guidelines and the affirmation defence in Maine' (1993) 19 Journal of Quality Improvement 355.

79 Florida Statute's Title (1992) chapter 408.02(9); RP Solomon, above, note 76.

80 M Mello, 'Of swords and shields: the use of clinical practice guidelines in medical malpractice litigation' (2000) 149 University of Pennsylvania Law Review 645.

81 Ibid. 
approach in the US is to permit guidelines to be used as both inculpatory and exculpatory evidence - what some commentators have referred to as 'a two-way street' ${ }^{82}$

\section{A two-way street}

There is a paucity of empirical evidence on 'real time' prevalence of the use of guidelines in medical litigation in the US. The study by Hyams and colleagues ${ }^{83}$ provides some helpful data. In this study, 48 per cent of lawyers surveyed reported having had at least one case per year in which guidelines played a role and 36 per cent had one case per year in which they played an 'important' role. Overall, the use of guidelines occurred in 7 per cent of the claims reviewed $(n=17)$. Of the 17, 12 had been used by the claimant (as a sword), 4 by the defendant (as a shield) and in 1 the use was indeterminate. The researchers also reviewed records of two professional liability insurance companies and surveyed 578 personal injury lawyers to determine the frequency and manner of the use of guidelines in litigation. They concluded that, although the use of guidelines was relatively infrequent, it might be increasing. ${ }^{84}$ Although guidelines were used by both defendants and claimants, the use by claimants was three times higher than the use by defendants. Claimants used guidelines successfully as a 'sword' in both the pre-trial and trial stages of litigation. ${ }^{85}$ The survey also indicated that despite a low prevalence of usage, guidelines still had a definite impact on the outcome of litigation. ${ }^{86}$ The guidelines used most frequently were those of the American College of Obstetricians and Gynaecologists, followed by the American Society of Anaesthesia. Specific characteristics defining or predicting the use of practice guidelines were difficult to identify and it appears that guidelines might be more frequently used in claims involving smaller hospitals or non-teaching hospitals, although the reasons for this are unclear. Possible uncorroborated explanations might be due to the more limited budgets of smaller hospitals and their potential to defend malpractice claims.

\footnotetext{
82 A Hyams et al., above, note 68.

83 Ibid.

84 Ibid.; in the Hyams study, 178 out of the 578 lawyers surveyed believed that the use of guidelines was increasing, while only 7 thought that it was decreasing.

85 See RP Solomon, above, note 76 at 154.

86 Of all responding lawyers 48 per cent stated that they had at least one case per year in which guidelines had played some part and 36 per cent had at least one case per year in which guidelines had played an important part. Twenty-two per cent reported that a clinical guideline had influenced a judge or jury in at least one case in the previous year.
} 
Although useful, the Hyams study has limitations. Only two insurance companies were surveyed, claims were relatively old (late 1980s) and there was no information available as to the proportion of cases in which a guideline may have been applicable but not used. It is not therefore possible to extrapolate the results to form an estimate of the current use of guidelines. The most significant finding was that guidelines were used for both inculpatory and exculpatory purposes. Proponents of systems for healthcare reform, clinicians and guideline developers should all be aware that guidelines are a double-edged sword. The potential for a two-way use in litigation might induce higher rates of compliance with guidelines in clinical practice. ${ }^{87}$

\section{Lessons from England and Wales and the US Experience}

In the UK and US both claimants and defendants deploy clinical guidelines in medical litigation. Experience from the US shows that authoritative guidelines are not automatically conferred the status of being definitive of the legal standard of care. The outcome of cases in which guidelines have been raised either as a shield by the defendant, or as a sword by the claimant, has depended upon the particulars of the case. It is unclear to what extent guidelines will simplify the system of medical litigation. However, there are at least three relevant lessons to be gleaned. These relate to (a) scrutiny of guidelines by the court before admissibility; (b) the continued need for expert testimony; and (c) whether guidelines will be deployed in a one-way or two-way fashion.

The US experience underscores the importance of ensuring that guidelines pass muster under applicable rules of evidence, particularly those concerning out-of-court statements. American courts apply a presumption against allowing out-of-court statements, or hearsay, into evidence because the speaker has not been sworn as a witness and is not available for cross-examination. American courts have made an exception to the hearsay rule on the basis that a clinical guideline is a 'learned treatise'. Although there is no rule that guidelines need to be so qualified before they are admitted as evidence in court, the 1993 US Supreme Court decision in Daubert created strict standards for the judicial evaluation of scientific data that are offered as evidence ${ }^{88}$ Before scientific evidence is admitted, it must be shown to be both reliable and relevant to the matter under consideration. ${ }^{89}$ Judges have a gate-keeping role in terms of evaluating and selectively admitting such evidence. ${ }^{90}$ The Federal Judicial

87 R Grilli and J Lomas, 'Evaluating the message: the relationship between compliance rate and the subject of a practice guideline' (1994) 32 Medical Care 202.

88 Daubert v Merrill Dow Pharmaceuticals Inc. 509 US 579 (1993).

89 The principle of Daubert validity is considered later.

90 Above, note 88 . 
Center has been active in educating judges in the methodology of statistics and epidemiology in order to prepare them for this challenge. ${ }^{91}$ The decision in Daubert encourages judges to take a more objective stance in evaluating the processes that underpin the development of guidelines before according such material evidential status in court. There is no effective hearsay rule in civil proceedings in England and Wales, although it has been questioned as to whether the court should not be asked in every case to determine whether a proffered guideline is reasonable and rational before relying on it as a standard of acceptable medical practice. ${ }^{92}$

Guidelines are issued by a variety of organisations, with possibly significant differences in approach. This could result in competing or conflicting guidelines and theoretically a defence to a 'guideline sword' would be to raise another as a 'guideline shield'. A claimant or defendant could challenge the credibility or authority of a guideline by showing that the developmental process was ineffective, thereby precluding its use in court. The credibility of guidelines used by the court would therefore need to be assured on the basis of pre-determined standards. ${ }^{93}$ The decision of Levine, in which conflicting guidelines on mammography were considered, illustrates the point. The claimant's experts raised the recommendations of the American Cancer Society, whereas the defendant's experts raised those of the American College of Obstetricians and Gynaecologists. ${ }^{94}$ The court acknowledged that there were two competent bodies of medical authority that differed and permitted the use of guidelines raised by the defendant on the basis that the defendant's conduct was strongly supported by respected professionals. Expert opinion will always be required in such cases and possibly also in assisting the court in evaluating Daubert - validity for the admissibility of guidelines. A claimant might still argue that even if a defendant provider has complied with clinical guidelines, the care provided constitutes the minimal necessary standard and is not a sufficient determinant of reasonable care under the circumstances. In

91 See, for example, FM Smith, SG Breyer, MA Berger, WW Schwarzer, JS Cecil, D Goodstein, DH Kaye, DA Freedman, DL Rubinfeld, SS Diamond, VA Lazear, MD Green, DM Freedman, LG Gordis, BD Goldstein, MS Henifin, HM Kipen, SR Poulter, GF Sensabaugh and H Petroski, Federal Judicial Center Reference Manual on Scientific Evidence (2nd edn, Washington, 2000) https://www.fjc.gov/content/321618/ reference-manual-scientific-evidence-second-edition-superseded accessed on 7 June 2021.

92 See, SM White, 'Letters to the editor' (2003) 96 Journal of the Royal Society of Medicine 254 and SM White, 'Not NICE advice' (2003) 15 Anaesthesia 295: these comments were raised in relation to NICE guidance on the use of ultrasound scans for the placing of central venous catheters which was the subject of some criticism.

93 This is developed later in the discussion.

94 Levine v Rosen 616 A 2d 623 (Pa 1992). 
a case of obstetric malpractice, where it was alleged that failure to monitor during labour resulted in a child's death, it was argued on appeal that although the standard of care provided complied with that of the American College of Obstetricians and Gynaecologists, nonetheless there was actionable negligence because those standards were the minimum expected standards, and that more should have been done by the defendant. ${ }^{95}$ Expert testimony will be required to determine what else should have been done. It therefore seems improbable that the need for expert testimony will be supplanted by the use of guidelines.

It is unlikely that guidelines will take root as a one-way process (used solely by claimants or just by defendants). The principal example of one-way use of guidelines as an affirmative defence in the Maine model has been indeterminate. Other potential models in US tort reform where guidelines may be regarded as carrying greater determinative one-way weight are the contract and judicial notice models. Problems with the contract model include lack of information, understanding and training that patients might have in terms of being able to choose from a range of guidelines, because of their comparative lack of clinical acumen. Decisions may be focused on short-term rather than long-term outcomes and a differential of choice might exist depending upon the source of funding for healthcare for that particular patient. The model of 'judicial notice' is one whereby the court takes note of guidelines as the standard of care with departures conclusively establishing negligence. This model proposes that with the help of an impartial court-retained medical expert, a set of guidelines would be identified as authoritative and applicable to the conduct in issue and would be adopted as the standard of care. Breach of the standard would be substantiated by proof that the physician diverged from the practice guidelines. Problematic issues have been raised regarding this model. Guidelines may not represent the perfect standard of care and may only represent the basic or minimal standard of care. The application of guidelines to a specific case is a matter of clinical judgement and expertise and this decision cannot be 'second guessed' by a judge. Furthermore, such a model would only be practicable where a single set of guidelines is recognised as authoritative by medical practitioners. These models are theoretical and untested, but undoubtedly would have inherent difficulties if applied in practice. ${ }^{96}$ The conclusion to be drawn is that the use of guidelines probably cannot be confined only to exculpatory use.

95 Jewett v Our Lady of Mercy Hospital, 82 Ohio App 3D 428; 612 NE 2d 724 (Ohio 1992).

96 RP Solomon, above, note 76 at 139. 


\section{Factors that Might Promote Greater Use of Guidelines}

\section{Clinical governance}

Clinical governance is the framework by which NHS organisations are accountable for safeguarding high standards of clinical care. ${ }^{97}$ This includes establishing clear lines of accountability and implementing comprehensive programmes that use evidence-based guidelines in clinical practice. The remit of clinical governance is wide and encompasses several key processes. Clinical effectiveness relies on data from primary research and systematic reviews and involves the development of standards of best practice through guidelines based on evidence. The underlying rationale of clinical effectiveness is to apply the best available knowledge to specific clinical interventions in order to achieve optimum processes and outcomes for patient care. Potential benefits of adherence to guidelines are linked inextricably to clinical audit and risk management. ${ }^{98}$ Audit represents a key component of good clinical practice and guidelines provide an external standard against which audit may be conducted. Guidelines also engage as part of the risk management standards and strategies. The Clinical Negligence Scheme for Trusts is a collective scheme with the remit of assisting Trusts to meet the costs of defending clinical negligence actions and promotes the use of guidelines as a means of reducing medical error. ${ }^{99}$ Integrated governance is the overarching framework that includes all contemporary NHS governance approaches. ${ }^{100}$ In theory, the lines of responsibility and accountability underlying integrated governance could advance and monitor the use of evidence-based guidelines in routine practice.

Under the current system tort liability for clinical negligence remains fault-based, despite several attempts at reform. ${ }^{101}$ A radical change would be a transition to an administrative or no-fault system for compensating medical injuries. A central tenet of such a proposal is that the system should make compensation decisions, and clinical guidelines that might bear on issues of causation or avoidability would likely play a pivotal role. A no-fault system

97 Department of Health, above, note 18.

98 For more detailed analysis, see DJ Tuffnell, 'Why guidelines? A medical perspective' in Guidelines: Law, Policy and Practice, above, note 13 at 19-35.

99 National Health Service Litigation Authority, General Clinical Negligence Scheme for Trusts: Clinical Risk Management Standards (HMSO, London, 2005).

100 Department of Health, Integrated Governance Handbook (HMSO, London, 2006).

101 This chapter does not propose to go into detail regarding fault-based and non-fault-based liability. For a discussion, see S Maclean, 'No fault liability in medical responsibility' in M Freeman (ed), Medicine, Ethics and the Law (Williams S Heinne and Co, New York, 1988); S Stephens and R Mann (eds), No Fault Compensation in Medicine (Royal Society of Medicine, London, 1989). 
in specific defined circumstances was proposed in the consultation document Making Amends, ${ }^{102}$ but was rejected subsequently by the Chief Medical Officer ${ }^{103}$ because the potential rise in claims would be far higher than under the present system. To be affordable, compensation would need to be set at substantially lower levels.

In the context of legislative reform the NHS Redress Act $2006^{104}$ provides a mechanism to facilitate rapid resolution of relatively small claims without recourse to civil proceedings. It would apply to personal injury or loss arising out of or in connection with a breach of duty of care owed to a person in relation to the diagnosis or treatment of a patient, or consequent to any act or omission by a healthcare professional provided that such an act or omission would merit compensation under existing tort-based principles. ${ }^{105}$ Although it was proposed by the Chief Medical Officer in Making Amends ${ }^{106}$ that a 'fairer test' than that accorded by Bolam should be used, this proposal failed ultimately to be included. The current test of eligibility for redress remains the Bolam standard. ${ }^{107}$ The Bill in its original form received short shrift from several consumer interest groups. ${ }^{108}$ The main thrust of such criticism was that claimants would not have the benefit of being represented by independent advisers, but by persons who are on the payroll of the defendant organisation. An alternative to Bolam is an 'avoidability test', whereby an adverse event will be compensatable except where it is the result of an unavoidable complication regardless of treatment or non-treatment. ${ }^{109}$ Although the Act has not yet been implemented it seems that proposals for reform may resurface again in the future perhaps moving away from the Bolam standard to evolve into one more dependent on guidelines.

Additional possibilities to no-fault liability could be achieved by channelling claims through alternative dispute resolution (ADR) or mediation. In March 2001, the Lord Chancellor made a pledge to employ ADR in

102 See Making Amends above, note 17.

103 Ibid.

104 The preceding House of Lords Bill 137 received its first reading in the House of Lords (1 March 2006) and its second reading on 5 June 2006.

105 An earlier version of the Bill was the subject of a study by the Constitutional Affairs Committee which provided a detailed statement on the Bill and its defects: see 'Compensation culture: NHS Redress Bill' 5th Report of Session 2005-06.

106 See Making Amends, above, note 17.

107 The charity 'Action against Medical Accidents' suggested an alternative 'avoidability test' which would mean that an adverse event could be compensated unless it was the result of an unavoidable complication.

108 Such as Action against Medical Accidents, the Patients' Association and Patient Advice and Liaison Service.

109 Ibid. 
suitable cases. This approach was considered to be more advantageous than a fault-based tort system, with considerable savings in legal costs as well as avoiding the acrimony of the adversarial process. ${ }^{110}$ Mediation might also offer satisfactory resolution to some claims of clinical negligence, whereby a neutral third party intervenes to facilitate negotiation. In both these processes, the use of guidelines, or lack thereof, could possibly be a significant factor in the settlement of claims.

\section{Patient-centred initiatives}

Government-led quality initiatives have sought to focus on a culture that is more patient-orientated rather than medically dominated. ${ }^{111}$ Patients' participation is statutorily defined and places a duty on NHS and Primary Care Trusts to 'make arrangements to involve and consult patients and the public in service planning, operation and in the development of proposals for changes'. ${ }^{112}$ Furthermore, patient organisations have played a crucial role in the development of the Expert Patients Programme, ${ }^{113}$ thereby creating a model for professionals and patients to work together to facilitate patient empowerment. The effect of this may be to encourage the implementation of guidelines at local level.

The National Patient Safety Agency (NPSA) was an independent organisation networking with reporting systems to receive and act on information about adverse events. Together with the Patients' Advocacy and Liaison Services that provided patients with information about their treatment it was expected that this might further contribute to enhanced demand for evidence-based practice and guidelines. The NPSA was a special health authority also responsible for ensuring that research was carried out safely through its responsibility for a central office for research ethics committees (COREC) and for addressing concerns on performance of individual doctors through the National Clinical Assessment Service (NCAS). ${ }^{114}$ The NPSA collected and analysed information to learn lessons, produce solutions and disseminate these in relation to adverse events. In the pursuit of learning, the NPSA undertook root cause analyses, which involved scrutiny of the circumstances surrounding adverse events for systems failure, human error and failure to follow operational processes

110 Department for Constitutional Affairs, Monitoring the Effectiveness of the Government's Commitment to Using Alternative Dispute Resolution (DCA, London, 2004).

111 J Bridgman, 'Learning from Bristol: healthcare in the 21st century' (2002) 65 MLR 241.

112 S. 11 Health and Social Care Act 2001.

113 See http://www.expertpatient.nhs.uk/ accessed on 5 March 2006.

114 As of 1 April 2005. 
or evidence-based guidelines and protocols. There was an expectation that this work would be in partnership with all stakeholders involved in patient safety. At Trust level these are the Trust board, the Patient Advice and Liaison Services, risk management departments, clinical governance committees and Chief Executives. At local level stakeholders include the Independent Complaints Advisory Service, Strategic Health Authorities, the coroner and the police; and at national level, the NHS Litigation Authority (now known as NHS Resolution), professional organisations such as the Royal Colleges, NICE, the Department of Health and the HC. The NPSA's wide remit was to strengthen the likelihood that clinical guidelines that relate to the prevention of medical injuries would be taken into account in its function of learning from adverse events and disseminating solutions.

Patient safety is an important challenge for modern health services and the NPSA enforced this through the Patient Safety Observatory and the National Reporting and Learning System. ${ }^{115}$ This was expected to identify trends and patterns in patient safety problems and assist working at local level by developing understandings of patient safety incidents and root causes. Evidence suggests that such initiatives have already had some effect, for example by using guidelines for the assessment and prevention of falls in older people. ${ }^{16}$ The adversarial nature of the clinical negligence system is at odds with the free reporting ethos needed to make patient safety initiatives work. This mismatch could be addressed by using guidelines as a tool for patient safety as well as for NHS Resolution claims management.

\section{Factors that Might Deter Use of Guidelines}

\section{Limitations of guidelines}

Guidelines have several limitations. There is a danger in applying generalised prescription of guidelines in a rigid fashion to every patient. This possible interference with clinical discretion gives rise to the accusation that guidelines can result in 'cookbook medicine'. There is always a need for flexibility in patient care and, although guidelines are designed to promote best practice, in any given clinical episode slavish adherence to guidelines may not be best practice for a particular patient. In medical practice many situations arise where the art of identifying patient problems and the application of clinical acumen to individual patient needs remains removed from the science and technological advances of the discipline. Evidence-based medicine cannot fully capture

115 National Patient Safety Agency, Building a Memory: Preventing Harm, Reducing Risks and Improving Patient Safety (HMSO, London, 2005).

116 Ibid. 
the art of medical practice, and there remains a need for clinical judgement and discretion. ${ }^{117}$ Additionally, guidelines are only as good as the underlying empirical evidence and the appropriateness of the conclusions reached on the basis of synthesis of evidence. The validity of guidelines may be undermined by weak research data as well as confounding factors and biases emanating from misconceptions, personal experiences and beliefs of the developers. ${ }^{118}$

The potential for using guidelines or evidence-based approaches to medicine as a mechanism for rationing healthcare has been flagged as a matter of concern. ${ }^{19}$ Decisions reflected in some guidance might be motivated predominantly by economic considerations. NICE, for example, has a specific remit to ensure the cost-effectiveness of treatment or interventional modalities and its guidance is frequently against clinical interventions on the basis of cost. A review of guidance by NICE in its first 5 years from 1999 up to April 2005 showed that 86 guidelines were published on 117 topics. Recommendations were distributed over four categories: recommended in 23 per cent; recommended with minor restrictions in 26 per cent; recommended with major restrictions in 32 per cent; and not recommended in 19 per cent. Just over a fifth of guidance produced by NICE gave a clearly affirmative recommendation. Of the negative recommendations, two-thirds were on grounds of insufficient evidence and one-third because of unacceptable cost-effectiveness. Overall, about one-quarter of interventions failed to be recommended based on economic considerations. Furthermore, it has been argued that as the work of NICE is critically important to the rational distribution of NHS funds, its appraisal of treatments should be insulated from external pressures, which includes pharmaceutical companies and patient lobby groups. ${ }^{120}$ If guidelines

117 See, for example, JR Hampton, 'Guidelines: for the obedience of fools and the guidance of wise men?' (2003) 3 Clinical Medicine 279; SH Woolf, R Groll, A Hutchinson, M Eccles and J Grimshaw, 'Guidelines: potential benefits, limitations and harms of guidelines' (1999) 318 BMJ 527; and D Black, 'The limitations of evidence' (1998) 32 Journal of the Royal College of Physicians of London 23.

118 RL Kane, 'Creating practice guidelines: the dangers of over reliance on expert judgement' (1995) 23 Journal of Law, Medicine and Ethics 62.

119 OF Norheim, 'Healthcare rationing: are additional criteria needed for assessing evidence-based clinical practice guidelines?' (1999) 319 BMJ 1426; B New, 'The rationing agenda in the NHS: Rationing Agenda Group' (1996) 312 BMJ 1593. More specifically in relation to guidance from NICE, see K Syrett, 'NICE work? Rationing, review and the "legitimacy problem" in the new NHS' (2002) 10 Med LR 1. For some of the issues regarding practical implications for Trusts, see A Samanta and J Samanta, 'Evidence-based medicine: a tool for rationalising or rationing healthcare?' (2005) 10 Clinical Governance: An International Journal 308.

120 J Raftery, 'Review of NICE's recommendations, 1999-2005' (2006) 332 BMJ 1266; RE Furner and SE Mc Dowell, 'How NICE may be outflanked' (2006) $332 B M J$ 1268. 
are perceived as a tool for rationing healthcare it is less likely that they will be used by the court as a determinant of the legal standard.

Another inherent problem with guidelines is that they may be proven wrong over time. For example, doubt has been cast over certain guidelines that have emanated from NICE. ${ }^{121}$ Moreover, where guidelines do not reflect current clinical practice $^{122}$ their potential to impact on legal proceedings may be small. Guidelines may not even reflect prevailing practice at the time of their adoption. The lack of concordance between guidance and prevailing practice has been one of the fundamental criticisms of using guidelines as the gold standard to set the legal standard of care. ${ }^{123}$ Because physician compliance with most guidelines is low, ${ }^{124}$ many guidelines cannot be said to be representative of prevailing medical practice. Despite the perceived authoritative status of NICE, the uptake even of these guidelines has been variable. ${ }^{125}$ Guidance is more likely to be adopted when there is strong professional support and when a stable and convincing evidence-base exists. ${ }^{126}$ Where there is a gulf between guidelines and custom, using guidelines as the legal standard of care could increase, rather than decrease, clinicians' uncertainty about what the law requires of them.

\section{Judicial reticence}

A particularly interesting finding of the study was that the majority of respondents stated that in their experience guidelines had not played a role in determining liability. Fifty-six per cent stated that guidelines had never played a role in determining liability in favour of the claimant and 52 per cent stated the same in respect of the defendant. Although lawyers may not be able to accurately recall the factors that underpin judicial decisions, observation might suggest a degree of scepticism about the weight of guidelines in determining the legal

121 For example, recent evidence demonstrates that the 'open mesh technique' rather than laparoscopic surgery is the preferred technique for repair of inguinal hernias.

122 R Choudhury and AMF Hassan, 'Guidelines are less clinical excellence than hindrance' (2003) 326 BMJ 114; K Bloor, N Fremantle, Z Khadjesari and A Meynard, 'The impact of NICE guidance on laparoscopic surgery for inguinal hernias: analysis of interrupted time series' (2003) 326 BMJ 578.

123 M Mello, above, note 80 .

124 H Teff, above, note 3; P Day, R Klein and F Miller, Hurdles and Levers: A Comparative US-UK Study of Guidelines (Nuffield Trust, London, 1998).

125 G Gill, 'Going Dutch? How to make guidelines work: an innovative report from Holland' (2001) Clinical Medicine 307; see also JR Hampton, above, note 117.

126 TA Sheldon, N Cullen, D Dawson, A Lanksher, K Lowson and I Watt, 'What is the evidence that NICE guidance has been implemented? Results from a national evaluation using time series analysis, audit of patients' notes and interviews' (2004) 329 BMJ 999 . 
standard. Judges might well believe that guidelines are for guidance rather than prescription.

Guidelines may not be decisive in determining the outcome of negligence cases because of a mismatch between the statistical concept of significance that forms the scientific evidence-base of medical interventions and the legal standard of proof. Clinicians, statisticians and jurists have different ways of thinking about whether a piece of information is 'significant' in proving or disproving a proposition, and there are inherent difficulties with trying to bridge this gap. ${ }^{127}$ Statistical thinking represents a relationship between the outcome and a number of underlying variables. Clinical thinking is an approximation derived from this relationship as opposed to being a certainty. What might appear to be statistically meaningful may not be clinically meaningful. Not all statistically significant differences lead to appreciably different clinical outcomes. If this is the case, it is questionable as to why legal significance ought to be attached to this information. Statistical and legal significance represent different constructs. Conventionally, statisticians require significance at the 95 per cent level or higher $(p<0.05){ }^{128}$ In civil litigation proof is required on a balance of probabilities at the 51 per cent level. In practice, these two kinds of 'significance' have been conflated. Courts have spoken of the 51 per cent standard as though all it requires is a $p$-value of 0.51 , but this is not correct, and remains greatly problematic when equated with clinical significance. ${ }^{129}$

A further problem of mismatch between clinical and legal thinking relates to the determination of causation. ${ }^{130}$ Causation in medicine is determined through consideration of a 'mosaic' comprised of a number of pieces of evidence, while causation in legal thinking is dependent upon a causal connection established by an unbroken chain of events. ${ }^{131}$ Clinical causation is dependent on the probability of injury occurring in the future based upon action that is taken currently, whereas legal causation is determined by a retrospective analysis of a chain of events leading to the injury sustained by a particular individual. The principal basis of medical causation is research evidence that is derived

127 M Mello, 'Using statistical evidence to prove the malpractice standard of care: bridging legal, clinical and statistical thinking' (2002) 37 Wake Forest Law Review 821.

128 JA Cuzick, above, note 49.

129 M Mello, above, note 127.

130 JR Matthews, 'Practice guidelines in tort reform: the legal system confronts the technocratic wish' (1999) 24 Journal of Health Politics, Policy and Law 275.

131 BJ Charlton, 'Attribution of causation in epidemiology: chain or mosaic?' (1996) 49 Journal of Clinical Epidemiology 105; on causation in legal theory see Chapter 4 of HLA Hart and T Honoré, Causation in the Law (Clarendon Press, Oxford, 1985): KG Sweeney, D MacAuley and DP Gray, 'Personal significance: the third dimension' (1998) 351 Lancet 134. 
from comparisons of groups (for example, in randomised clinical trials), rather than an examination of what happens to a specific individual within a group. The law is more concerned with what happens to the individual as opposed to medical outcomes in relation to groups because the objective of the tort system is to put an injured person into the position that he or she would have been in had the tort not occurred. Medical research, and consequently guidelines, can never definitively predict what might happen to an individual. Clinical outcomes including those based on guidelines are viewed probabilistically as to what might happen; juristic thinking on the other hand is in terms of a binary model of either liability or no liability. The inherent differences that underlie thinking within medical and legal cultures may affect judges' inclination to embed guidelines in making liability determinations.

It may also be necessary for the courts to distinguish between what are regarded as 'appropriateness' guidelines and 'standard-of-care' guidelines. ${ }^{132}$ Appropriateness guidelines are developed for the purpose of reducing the rates of various procedures between individual clinicians to reduce variations in care and may also be motivated by financial concerns. Standard-of-care guidelines are aimed to reduce medical injury and maximise clinical effectiveness, and are driven by standards of care consistent with patient safety and quality rather than sole financial considerations. The courts may (and indeed should) be more cautious about applying appropriateness guidelines as the standard of care than they are about applying standard-of-care guidelines and telling the difference between the two may not be straightforward. Furthermore, guidelines might be promulgated by insurance companies with a view to reducing insurance premiums, although it is unlikely that insurance companies will insist on the mandatory use of such guidelines, possibly because of the potential conflicts that could arise in the event of a suit being based on the content of the guidelines. ${ }^{133}$ In a case where failure to diagnose breast cancer was alleged, ${ }^{134}$ a possible reason for the court's refusal to admit guidelines relied upon by the defendant might have been that they were promulgated by

132 TA Brennan, 'Methods for setting priorities for guideline development: medical malpractice' in MJ Field (ed), Setting Priorities for Clinical Practice Guidelines (National Academy Press, Washington, 1995).

133 This is mainly a concern with the use of guidelines in the US as seen in the development of the American Society of Anaesthesiologists' guidelines to prevent hypoxic accidents by the use of certain equipment and effective equipment maintenance. Although this particular project was highly successful in reducing adverse events and bringing down insurance premiums, it is unlikely that guidelines will be mandated by insurance companies: see Solomon, above, note 76.

134 Quigley v Jobe 851 P 2D 236 (Colo. CT App 1992). 
a private insurance company as part of an insurance contract, and may not have represented standard medical practice. ${ }^{135}$

Judges may be reluctant to lean too heavily on guidelines because authors of guidelines are not usually called as witnesses. In the absence of the ability to cross-examine the authors there may be a judicial reluctance to accept their pronouncements as dispositive of the case. ${ }^{136}$ Indeed, guidelines may be overshadowed by live testimony provided by expert witnesses. This is exemplified in Loveday $v$ Renton which involved consideration of contraindications to the pertussis vaccine. ${ }^{137}$ In explaining his preference for the evidence of expert witnesses over written material published by learned societies, the judge opined: 'The evidence contained in the contraindications against pertussis vaccination published from time to time in this country by the DHSS and similar bodies in other countries cannot be relied upon as though it was evidence of qualified experts not called in witness' (emphasis added).

Guidelines may not always represent or even influence contemporaneous medical practice. In a recent study the evidence was tenuous that NICE guidelines were implemented in a manner that they actually had an impact on clinical practice. ${ }^{138}$ Uptake of NICE guidelines has been variable and to some degree inconsistent. ${ }^{139}$ It is likely that implementation of such guidance would have been improved if the evidence-base was strong and relatively stable, and if adequate funding was available to support, disseminate and implement such guidance. ${ }^{140}$ In the absence of clear evidence that guidelines are actually implemented and followed, even when they are provided by an authoritative body such as NICE, the courts may be reluctant to actively adopt them in determining the standard in clinical negligence.

\section{Challenging Guidelines}

\section{Standards}

Guidelines created by professional bodies of esteem and standing are likely to carry greater authority. ${ }^{141}$ The process through which guidelines are developed

135 This is of particular interest as it re-emphasises the importance of Troy Brennan's distinction of 'appropriateness of guidelines' versus 'standard-of-care' guidelines in the use of medical malpractice litigation.

136 Loveday v Renton [1990] 1 Med LR 117.

137 Ibid.

138 TA Sheldon et al., above, note 126.

139 Ibid.

140 Further correspondence and discussion of this paper can be found in the $B M J$ (2005) 330 at 1084-6.

${ }^{141}$ J Grimshaw and IR Russell, 'Achieving health gain through clinical guidelines: developing scientifically valid guidelines' (1994) 2 Quality in Healthcare 204. 
should be robust, exacting and evidence-based. Ideally guidelines should reflect actual clinical practice among respected specialists in the field.

Many approaches to guideline development have been taken, but credibility can be enhanced by using a hierarchy of development strategies. ${ }^{142}$ Having ascertained an area of need, relevant stakeholders are invited to form a guideline development group. Evidence needs to be searched for and obtained, and graded according to its hierarchy. The meticulous appraisal of scientific evidence and its strength are crucial to the status of authority that guidelines would carry. ${ }^{143}$ Guidelines are then developed, piloted and refined. Dissemination and implementation strategies promote use and credibility. Design and presentation are key to successful implementation. Several diverse methods need to be used in order to disseminate guidelines successfully. Extensive dissemination strategies underpin the contention that the guideline is meant for widespread use and that medical practitioners should be on notice regarding its content and application. ${ }^{144}$

The proliferation of guidelines has generated a system for guideline appraisal. ${ }^{145}$ Several questions covering specific areas such as the guideline development process, content, presentation and applicability have been developed and, by answering these questions, an estimate of the guideline's overall worth is made. In 1998 the US government launched an internet website intended to make evidence-based clinical practice guidelines widely available to healthcare professionals. The National Guidelines Clearinghouse (NGC) adopted minimum criteria of inclusion on the website. Guidelines should contain systematically developed statements that have recommendation strategies or information that assist healthcare professionals and patients in making informed decisions about appropriate healthcare. Guidelines should be produced by relevant professional organisations and those that are developed by individuals who are not officially sponsored or supported would not meet the inclusion criteria for NGC. There was a requirement that corroborating documentation could be produced and verified to confirm that a systematic literature search and review of existing scientific evidence in peer-reviewed jour-

\footnotetext{
142 SH Woolf, 'Practice guidelines: a new reality in medicine - methods of developing guidelines' (1992) 152 Archives of Internal Medicine 946.

143 DJ Tuffnell and J Wright, 'Designing clinical guidelines: steps and procedures' in Guidelines: Law, Policy and Practice, above, note 13 at 37-52.

144 NICE, for example, has a dissemination strategy that circulates its guidelines widely.

145 F Cluzeau, P Littlejohns, J Grimshaw and G Feder, 'Draft appraisal instrument for clinical guidelines' in Royal College of General Practitioners, Clinical Guidelines Working Group, The Development and Implementation of Clinical Guidelines (The College, Exeter, 1995) 1-46.
} 
nals had been performed. Any gaps in the process needed to be identified and stated clearly. Finally, the most recent version of guidance had to be produced together with documented evidence that this had been developed, reviewed or revised within the last 5 years. ${ }^{146}$ At this time there was no equivalent quality assurance body in the UK, although it was thought that the performance framework for the NHS driven by 'Standards for Better Health' ${ }^{147}$ might have been the first step in that direction.

\section{Institutional legitimacy}

Managers and healthcare professionals have limited budgets and competing claims for services. It falls upon them to prioritise claims, and evidence-based medicine may be used to address the problem of limited healthcare resources. ${ }^{148}$ On the basis of distributive justice, to ensure a more effective service for all, best scientific evidence could be used to inform the way resources are prioritised to avoid input into what might be deemed 'ineffective' treatment. ${ }^{149}$

A practical approach to prioritisation was defined and used to programme budgeting and marginal analysis followed by pragmatic considerations in determining how resources are allocated at local and institutional levels. ${ }^{150}$ Programme budgeting and marginal analysis included determining locally relevant needs, identifying where services could grow and where resources could be released through improved efficiency, evaluating investments and reallocating resources. Several practical and ethical considerations had to be taken into account, such as establishing the objective of the institution, establishing appropriate advisory panels with key stakeholders, ensuring implementation of results, reviewing, re-evaluating and reallocating resources.

As part of prioritising resources, an institution or Trust may decide not to accept or implement guidelines in a certain clinical area. ${ }^{151}$ To be regarded as legitimate, however, an institution must be based upon an order that is worthy

146 Funding to support the National Guidelines Clearinghouse ended in 2018.

147 Department for Health, Standards for Better Health (Department of Health, London, 2004).

148 R Klein, 'The NHS and the new scientism: solution or delusion?' (1996) 89 Quarterly Journal of Medicine 85.

149 OF Norheim, 'Clinical guidelines: healthcare rationing and accountability for reasonableness' in Clinical Guidelines: Law, Policy and Practice, above, note 13 at $161-80$.

150 S Peacock, D Ruta, C Mitton, C Donaldson, A Bate and M Murtagh, 'Using economics to set pragmatic and ethical priorities' (2006) 332 BMJ 482.

151 In $R v$ North Derbyshire HA, ex $p$ Fisher [1997] 8 Med LR 327: the health authority refused to provide beta interferon treatment for multiple sclerosis in contravention of national guidelines. 
of recognition and respect, ${ }^{152}$ and that its decision-making process is patently transparent through application of the framework for the 'accountability for reasonableness'. ${ }^{153}$ There are three main conditions: publicity, relevance and appeal. A fourth condition, enforcement, has an oversight function; its purpose is to ensure that the first three conditions have been met in a satisfactory manner. It was suggested that this framework had important implications for clinical governance at all levels ${ }^{154}$ and would apply to institutional decisions not to endorse or use nationally accepted guidelines. The publicity condition required that the rationale underlying decisions was explicit and publicly accessible. The relevance condition required decision-makers to take into account factors relevant to all key stakeholders and that they were sure that exercise of their discretionary powers had been unfettered, particularly with respect to the interests of groups who might be made more vulnerable in the future as a consequence of a negative determination not to use guidelines. ${ }^{155}$

There was no explicit mention in this model for public participation in decision-making. ${ }^{156}$ The central theme of the new NHS was to empower patients, with more active involvement of patients and the public within the framework of due process to enhance legitimacy. It is only recently that social value judgements have been considered as a principle to underpin the development of guidelines. ${ }^{157}$ Setting limits on treatment options through guidelines should involve patients and the public. ${ }^{158}$ The Freedom of Information Act 2000 allows for information regarding decision-making in institutions to be made freely available to the public. ${ }^{159}$ A potential claimant who might wish to challenge the process would be entitled to such information through the provisions of the Act. The appeals condition allows for an internal review of the decision-making process.

\section{Judicial review}

The courts can provide a mechanism for external scrutiny and enforcement of guidelines affecting the distribution of healthcare resources when other pro-

152 See K Syrett, above, note 119.

153 N Daniels and J Sabin, 'Limits to healthcare: fair procedures, democratic deliberation and the legitimacy problem for insurers' (1997) 4 Philosophy in Public Affairs 303.

154 See A Samanta and J Samanta, above, note 119.

155 Ibid. and A Samanta, J Samanta and M Gunn, above, note 20.

156 A Samanta and J Samanta, above, note 154.

157 See, the post consultation draft: National Institute for Health and Clinical Excellence, 'Social value judgments: principles for the development of NICE's guidance' (21 September 2005).

158 N Daniels and J Sabin, above, note 153.

159 S. 1(1). 
cesses have been exhausted or unsuccessful. The case of $R v$ North Derbyshire Health Authority, ex parte Fisher ${ }^{160}$ concerned failure to follow national guidance regarding beta interferon treatment for multiple sclerosis. The health authority adopted a policy under which funding for the treatment would be considered only for patients participating in a randomised controlled trial. This was contrary to the guidance in a government circular, which stated that the patient should be referred from primary care to secondary care specialist neurological services for assessment. The court held that as there was no such randomised controlled trial ongoing, the health authority's failure to adopt the policy effectively amounted to a ban on treatment with beta interferon and while it was not mandatory to follow the national guidance any failure to do so had to be justified. In $R v$ Secretary of State for Health, ex parte Pfizer, ${ }^{161}$ the guidance itself was at issue. The pharmaceutical company, Pfizer, challenged the lawfulness of a Department of Health circular containing guidance on the prescription of one of Pfizer's products, sildenafil (Viagra). The guidance stated that 'doctors should not prescribe sildenafil. Health authorities are also advised not to support the provision of sildenafil at NHS expense ... other than in exceptional circumstances'. ${ }^{162}$ The court held that the circular was unlawful because in stating that the drug should not be prescribed, it was creating a mandatory prohibition, and therefore put primary care physicians in breach of their terms of service by overriding their clinical judgement.

These two cases reveal that courts may require justification when guidance excludes or restricts treatment modalities. This, in a sense, is an enforcement of the reasonableness condition, whereby reasons that are relevant and fair need to be advanced by decision-makers in support of decisions that have been taken. However, the vigour with which the judiciary is willing to oversee the process of limit-setting decisions in the economics of healthcare has been questioned. Following the decision at first instance in the Viagra litigation, the Secretary of State, utilising powers under the National Health Service Act 1997, added Viagra to the schedule of drugs whose availability on the NHS was limited to specific medical conditions or classes of patients. The effect was that Viagra was partially 'blacklisted' except to those who were already receiving treatment and to those with specific medical conditions. This was challenged under the 'Transparency Directive' 89/105/EEC on the basis that some form of explanation, with regard to the relative priority of the treatment of erectile dysfunction against other non-life-threatening conditions, should be

160 Above, note 151.

$161 R v$ Secretary of State for Health, ex parte Pfizer [1999] Lloyd's Rep. Med. 289.

162 Ibid. 
provided. The Court of Appeal ${ }^{163}$ found that there had been no breach of the Directive. ${ }^{164}$ This result has been seen as disappointing, an indication of the judiciary's unwillingness to engage more fully with rationing in the NHS. It has also prompted questioning of judicial review as an effectual mechanism for facilitating legitimacy in resource-allocation decision-making. ${ }^{165}$

Finally, it must be acknowledged that the NHS is underfunded and this may need to be taken into account when determining the standard of care owed to patients. Although this suggestion might appear controversial it has been argued that its adoption would harmonise negligence cases with judicial review decisions. ${ }^{166}$ Whether the courts will take a similar approach to guidelines that are challenged as being reflective of the standard of care in litigation remains to be seen.

\section{CONCLUSION}

There are advantages to using well-constructed and authoritative clinical guidelines to establish the standard of care in medical litigation. Such an approach could elevate the quality of healthcare and provide medical practitioners with greater certainty as to what is expected from them by law. However, guidelines have limitations and represent a generalisation of empirical evidence which may not always be applicable due to the need for the exercise of clinical judgement. Therefore, their use in litigation requires caution and a careful and structured framework to ensure that they are applied appropriately. We suggest that this approach should tread a middle path between the traditional Bolam approach of basing legal duty solely on customary practice as established by expert testimony and the alternative notion that guidelines should definitively establish the standard of care. The latter approach will often prove too rigid and unrealistic, and does not allow for inherent variations in patients, their responses to treatment and clinical judgement.

Governmental agenda for quality in healthcare, professional reform and societal shifts all support greater integration of guidelines into clinical negligence litigation. Despite wide interest in potential uses of guidelines, to our knowledge, our survey of solicitors and barristers is the first study to provide empirical data about their use in medical negligence litigation. We found that

$163 R$ (on the application of Pfizer Ltd) $v$ Secretary of State for Health [2002] EWCA Civ 1556.

164 For a detailed analysis of the issues argued, see K Syrett, 'Impotence or importance? Judicial review in an era of explicit NHS rationing' (2004) 67 MLR 289.

165 Ibid.

166 C Witting, 'National Health Service rationing: implications for the standard of care in negligence' (2001) 21 OJLS 443. 
a high percentage of lawyers were familiar with guidelines and had observed guidelines being used in recent medical negligence cases by both claimants and defendants. The majority thought that guidelines would be used to a greater degree in the future.

A limitation of the empirical study was the relatively low response rate, a problem commonly encountered in surveys of busy professionals, particularly when no honorarium is paid for participation. ${ }^{167} \mathrm{~A}$ low response rate raises the possibility of non-response bias. The respondents in the survey appeared to have considerable experience in terms of both years of legal practice and clinical negligence caseload, and it is possible that they have a greater awareness of guidelines and also use them more frequently than less experienced lawyers who did not participate in the survey. While the generalisability of results may be limited, the data nonetheless provided the only available evidence at that time as to how guidelines were being used in litigation from the perspective of solicitors and barristers. Future studies could seek to determine the prevalence of the use of guidelines through analysis of medical litigation cases; use of focus groups to explore how solicitors, barristers and judges believe guidelines should be used; and analysis of the extent to which use of guidelines influence trial outcomes and pre-trial settlements.

167 DA Asch, MK Jedrziewski and NA Christakis, 'Response rates to mail surveys published in medical journals' (1997) 50 Journal of Clinical Epidemiology 1129. 